\title{
Prevalence of Liver Cancer in Isfahan Province, Iran
}

\author{
Zahra Tolou-Ghamari*, Farhad Tadayon, Hamid Mazdak \\ Isfahan Kidney Transplantation Research Center, Alzahra Research Institute, Isfahan University of Medical Sciences. \\ Isfahan/Iran
}

\section{ARTICLE INFO}

Article history:

Received : 12 July 2018

Reviewed: 02 August 2018

Accepted : 27 August 2018

Keywords:

Liver, Cancer, Incidence, Isfahan

\begin{abstract}
A BSTRACT
Background: Liver cancer remains to grow worldwide. We aimed to describe the period prevalence (PP) and incidence rates (IrS) for liver cancer in Isfahan Province that is located in the center of Iran and ranked as the third province in terms of population.
\end{abstract}

Methods: Information related to the Surveillance, Epidemiology, and End Results; (SEER) was collected from the Isfahan Cancer Registry. Period prevalence (PP) was calculated per 100,000 people. The cancer sites studied were defined according to the International Classification of Diseases (ICD-O; Third Edition) and recorded by topography code (C22).

\begin{abstract}
Result: Among all registered liver cancer patients, $57 \%$ of the 920 cases were male. The mean age of the patients was $65.9 \pm 16.8$ years. Reported age in $13 \%$ of the patients was less than 50 years and as high as $84 \%$ were in between 50 to 90 years. With a total PP of 18.5 per 100,000 people, this value was $24.4 \%$ higher in males when compared to females (16.8 vs. 20.9). In the previous years, incidences were 3.9 (2011-2012), 5.3 (2012-2013), 4.9 (2013-2014) and 4.2 (2014-2015) per 100,000 people. There were $89 \%$ reported deaths among the total population.
\end{abstract}

Conclusion: The PP for liver cancer in male population was approximately $24.4 \%$ higher than females. There was a $7.7 \%$ increase in the Irs over the study period. Further study toward estimation of the proportion of the causes of liver cancer and deaths due to infection of hepatitis $B$ and $C$ virus, exposure to aflatoxin, alcohol drinking and smoking seem to be advantageous. Therefore, the plan of healthcare system should focus on greater effort toward strategic evidence-based pharmacotherapy in Isfahan province/Iran.

\section{INTRODUCTION}

According to previous published articles, primary liver cancer (LC) was one of the most frequently occurring cancer in the world and the second largest contributor to cancer mortality. The prevalence and incidence of diseases related to liver seems to show similar picture but there are variation related to trend in risk factors.

Globally, the most common histology in LC is hepatocellular carcinoma (HCC; 80\%), a tumor of the parenchymal cells of the liver. The second most common histology is intrahepatic cholangiocarcinoma (ICC; 15\%), which arises in the cholangiocytes of the intrahepatic bile duct. Large geographic disparities in incidence and mortality of all types of liver cancer exist (1-6). Besides many causes, hepatocellular carcinoma could also be the result of chronic liver disease in patients with non-alcoholic fatty liver disease (7).

Related to the world's burden of diseases, report confirms a $75 \%$ occurrence of disease in Asia, with China accounting for over $50 \%$. Northern Europe, the Middle East, Oceania, North and South America were marked as the countries with the lowest incidence rates. Mongolia was reported as the country with the highest agestandardized incidence rate of 78.1 per 100,000 people (5).

Isfahan province covers approximately 107,027 km2 and is located in the center of Iran, a country in Southwest Asia. Isfahan province ranked as the third province in terms of population (498,210 people) after Tehran and Mashahad. Between the years of 2003 to 2009, a published study confirmed that there were 3,584 cases of liver cancer in Iran (8). Another article in the year of 1990 and 2015 reported that distinct age 
standardized LC incidence rate were 1.56 in female versus 2.03 in male per 100,000 people in Iran (9). According to a published article, the mortality of liver cancer has changed, as the rate of death has increased from 4.78 (2006) to 5.37 (2010) in Iran (10). Studies in 2012 that include all registered Iranian cancer cases confirmed 1,567 patients with liver cancer corresponded to a crude rate of 2.1 and a standardized rate of 2.5 per 100,000 people (11).

In order to develop the existed technical approach, understanding epidemiology of liver cancer could lead to improved pharmacotherapy or surgical management. Therefore, this study aimed to investigate the period prevalence and incidence rates of liver cancer in Isfahan Province Iran.

\section{MATERIAL AND METHOD}

The study was conducted in the Isfahan Kidney Transplantation Research Centre (IKTRC). This retrospective survey was a part of a project that was approved by the Institutional Review Board (No. 295115). The Isfahan Cancer Program is intended to record all cancer cases in Isfahan. All pathology centres and other information sources such as hospital medical records, mortality data provinces, haematologyoncology centres, radiotherapy centres, are obliged to report their data to the Isfahan Cancer Office of Disease Control and Prevention (CDC). The management arm of the program is the deputy of research in the Isfahan University of Medical Sciences. The cancer sites studied were defined according to the International Classification of Diseases (ICD-O; Third Edition). Liver cancer was defined by topography code (C22). The inclusion criteria were associated to all recorded cases with liver cancer and there were not any exclusion criteria.

Data, with linkage to using of the de-identified patient name and surname, demographic such as age and gender, final code for cancer diagnosis and date of the diagnosis were recorded.

The total population for Isfahan province was obtained from the Isfahan Program and Budget Management Organization. Period Prevalence was calculated as the proportion of total cases over the period in year 2011 and 2015 to population at risk during the same period of time $\times 100,000$. Incidence rates (Irs) was calculated by dividing new cases of cancer during a given time period to population at risk during the same period of time $x 100,000$. The statistical analysis of d-Base was performed using Microsoft Excel and SPSS v. 20 (Chicago, IL, USA) for windows $(2,3)$.

\section{RESULTS}

There were 920 recorded cases, in which 57\% were males. The normality distribution of age was tested by the Kolmogorov-Smirnov test and to show continuous variable, the data was shown as mean \pm standard deviation (SD). The mean (SD) age was 65.9 (16.8) years. As shown in Figure 1, the most incident of liver cancer (83\%) occurred between the ages of 50 to 90 years old. Demographic and epidemiology characteristic of patients with liver cancer are shown in Table 1.

Table 1. Demographic and epidemiological characteristics of the patients with liver cancer

\begin{tabular}{|c|c|c|c|c|c|c|c|c|c|}
\hline \multirow[b]{2}{*}{$\begin{array}{l}\text { Population } \\
\text { studied }\end{array}$} & \multirow[b]{2}{*}{$N$} & \multirow[b]{2}{*}{$\begin{array}{l}\text { RLC, } \\
n\end{array}$} & \multirow[b]{2}{*}{$\begin{array}{l}\mathrm{RD}, \\
n\end{array}$} & \multirow[b]{2}{*}{$\begin{array}{l}\text { Age, year, } \\
\text { mean (SD) }\end{array}$} & \multirow[b]{2}{*}{ PP } & \multicolumn{4}{|c|}{ Ir (\%) } \\
\hline & & & & & & $\begin{array}{l}2011- \\
2012\end{array}$ & $\begin{array}{l}2012- \\
2013 \\
\end{array}$ & $\begin{array}{l}2013- \\
2014\end{array}$ & $\begin{array}{l}2014- \\
2015\end{array}$ \\
\hline Total & 920 & 105 & 815 & $65.9(16.8)$ & 18.5 & 3.9 & 5.3 & 4.9 & 4.2 \\
\hline Females & 393 & 42 & 351 & $65.2(17.0)$ & 20.9 & 3.4 & 4.3 & 4.6 & 3.6 \\
\hline Males & 527 & 63 & 464 & 66.4 (16.6) & 16.0 & 4.6 & 6.3 & 5.3 & 4.7 \\
\hline
\end{tabular}

RLC: reported living cases, RD: reported death, PP: period prevalence, Ir: Incidence rate.

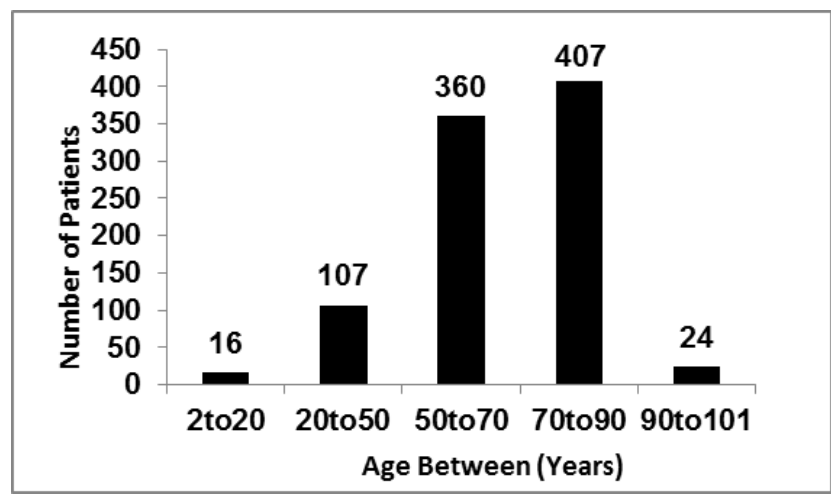

Figure 1. Distribution of age in patients with liver cancer

The calculated PP was 18.5 per 100,000 people, which corresponded to a PP of 16.8 per 100,000 in females and 20.9 per 100,000 in males. Figure 2 shows the Irs for liver cancer between the year of 2011-2015 associated to each gender.

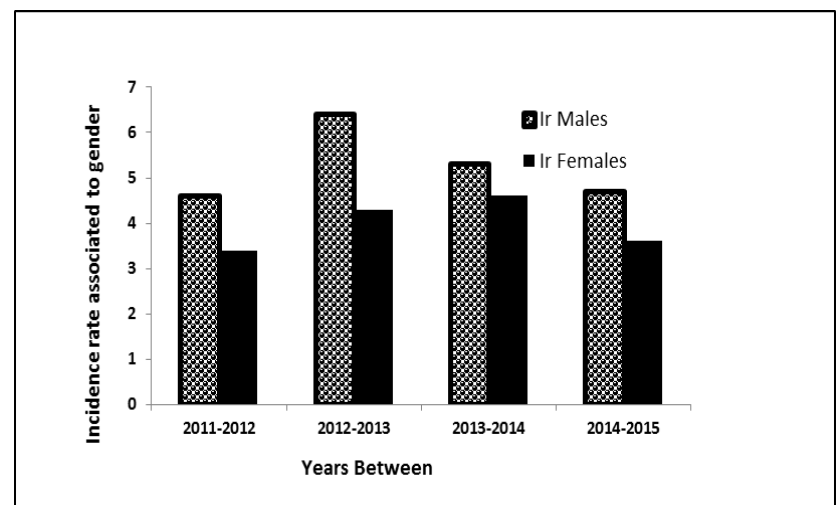

Figure 2. Incidence rate of liver cancer associated to gender 
The Irs for the related years of study for both genders comprised of females vs. males were: 3.9 (3.4 vs. 4.6), 5.3 (4.3 vs. 6.3 ), 4.9 (4.6 vs. 5.3 ) and 4.2 (3.6 vs. 4.7 ) per 100,000 people. Out of total population studied $(n=920), 815$ (89\%) were reported; that corresponded to 351 deceased females and 464 males respectively.

\section{DISCUSSION}

On the global scale, hepatocellular carcinoma was reported as a major contributor to both cancer incidence and mortality (5). The incidence could be explained by the distribution and natural history of the hepatitis B and C viruses (6). More than 240 million individuals worldwide are infected with chronic hepatitis B virus (HBV). Among individuals with chronic HBV infection who are untreated, $15 \%$ to $40 \%$ progress to cirrhosis, which may lead to liver failure and liver cancer (14).

In this study, the total PP for liver cancer in Isfahan province was 18.5 per 100,000 persons that corresponded to a value of 20.9 for males and 16.8 for females. This is consistent with published articles that also confirmed higher values in males (15). Age reported liver cancer was $13 \%$ in patients less than 50 years and as high as $84 \%$ between 50 to 90 years. Previous publication confirmed that the age-dependent patterns in the gender difference in the incidence of hepatocellular carcinoma support the hypothesis of a protective role of estrogens16. In the United States, liver cancer was reported as the fastest increasing cancer and is one of the leading causes of cancerrelated death in New York City, with wide disparities among neighborhoods (16). Experimental and molecular epidemiological studies indicate important roles for changes in insulin signaling, adipose tissue-derived inflammation and sex hormone pathways in mediating the association between adiposity and gastrointestinal cancer (17). This study is similar to previous study that mentioned liver cancer as one of the most common causes of death in the world (18).

In congruence with previous publication, gastrointestinal cancers remain the most prevalent cancer in many developing countries such as Iran. An upward trends in age adjusted incidence (males 22.9 to 74.2 and females 14.9 to 44.2 ), prevalence (males 52.6 to 177.7 and females 38.3 to 111.03 ), and mortality (males 14.6 to 47.2 and females 9.6 to 28.2 ) rates per 100,000 people for the period of 2001 to 2010 was reported (17). There were $89 \%$ reported death among all 920 patients with liver cancer. Cigarette smoking, particularly recent smoking, knowingly augmented mortality risk from liver cancer (18). HBV, HCV, aflatoxin, alcohol drinking and tobacco smoking could be responsible for liver cancer mortality and incidence too (19).
Finally, the result of this study confirmed a $7.7 \%$ increase in the incidence rate of liver cancer over the study period. Due to the presence of different categories of socio-economic, behavioral and ecological risk factors regarding access to specialized pharmacotherapy and surgical facilities (20-21), further study toward dissimilar structures associated to liver cancer management in Isfahan Province/Iran seem to be advantageous. Therefore authorities can use this data for scheduling health care and assigning incomes in public health.

\section{CONCLUSION}

The PP for liver cancer in male population was approximately $24.4 \%$ higher than females. There was a $7.7 \%$ increase in the Irs over the study period. Further study toward estimation of the proportion of the causes of liver cancer and deaths due to infection of hepatitis B and $C$ virus, exposure to aflatoxin, alcohol drinking and smoking seem to be advantageous. Therefore, the plan of healthcare system should focus on greater effort toward strategic evidence-based pharmacotherapy in Isfahan province/Iran.

\section{ACKNOWLEDGMENT}

The present work was supported by the Research Fund of Isfahan Kidney Transplantation Research Center, Isfahan University of Medical Science, and Project No. 295115. The author expresses many thanks to all cancer registry staffs and professors; Mehrdad Mohammadi, Massieh Saboori.

\section{CONFLICT OF INTEREST}

The author declares no conflict of interests for this study.

\section{FUNDING}

There was no any financial support associated to this study.

\section{REFERENCES}

1. Pimpin L, Cortez-Pinto H, Negro F, Corbould E, Lazarus JV, Webber L, et al. Burden of liver disease in Europe: epidemiology and analysis of risk factors to identify prevention policies. J Hepatol. 2018 Sep;69(3):718-735.

2. Mazdak H, Tolou-Ghamari Z. Preliminary study of prevalence for bladder cancer in Isfahan Province, Iran. Arab J Urol. 2018 Jan 17;16(2):206-210.

3. Ghamari ZT. Prevalence of lung cancer in Isfahan Province, Iran. J Egypt Natl Canc Inst. 2018 Jun; 30(2): 57-59.

4. Ghamari ZT, Palizban AA, Tredger JM. Clinical monitoring of tacrolimus after liver transplantation using pentamer formation assay and microparticle enzyme immunoassay. Drugs RD. 2004;5(1):17-22. 
5. McGlynn KA, Petrick JL, London WT. Global epidemiology of hepatocellular carcinoma: an emphasis on demographic and regional variability. Clin Liver Dis. 2015 May; 19(2): 223-38.

6. Bosch FX, Ribes J, Díaz M, Cléries R. Primary liver cancer: worldwide incidence and trends. Gastroenterology. 2004 Nov;127(5):S5-S16.

7. Albhaisi S, Sanyal A. Recent advances in understanding and managing non-alcoholic fatty liver disease. F1000Res. 2018 Jun $11 ; 7$.

8. Mirzaei M, Ghoncheh M, Pournamdar Z, Soheilipour F, Salehiniya $\mathrm{H}$. Incidence and trend of liver cancer in Iran. J Coll Physicians Surg Pak. 2016 Apr;26(4):306-9.

9. HajizadehN, Baghestani AR, Pourhoseingholi MA, Najafimehr H, Fazeli Z, Bosani L. Bayesian correction model for over-estimation and under-estimation of liver cancer incidence in Iranian neighboring provinces. Gastroenterol Hepatol Bed Bench. 2017;10(I1):S54-S61.

10. Tang LSY, Covert E, Wilson E, Kottilil S. Chronic hepatitis B infection: a review. JAMA. 2018 May 1;319(17):1802-13.

11. Lee EY, Mai TTX, Chang Y, Ki M. Trends of liver cancer and its major risk factors in Korea. Epidemiol Health. 2015; 37.

12. Liu P, Xie SH, Hu S, Cheng X, Gao T, Zhang C, et al. Agespecific sex difference in the incidence of hepatocellular carcinoma in the United States. Oncotarget. 2017 Jul 12; 8(40): 68131-7.

13. Kamath GR, Taioli E, Egorova NN, Llovet JM, Perumalswami PV, Weiss JJ, et al. Liver cancer disparities in New York city: a neighborhood view of risk and harm reduction factors. Front Oncol. 2018 Jun 14;8:220.

14. Murphy N, Jenab M, Gunter MJ. Adiposity and gastrointestinal cancers: epidemiology, mechanisms and future directions. Nat Rev Gastroenterol Hepatol. $2018 \mathrm{Jul}$ 3.

15. Park J, Jee YH. Age-period-cohort analysis of liver cancer mortality in Korea. Asian Pac J Cancer Prev. 2015;16(18):8589-94.

16. Pang $Q$, Qu K, Zhang J, Xu X, Liu S, Song $S$, et al. Cigarette smoking increases the risk of mortality from liver cancer: a clinical-based cohort and meta-analysis. J Gastroenterol Hepatol. 2015 Oct;30(10):1450-60. 